\title{
Progress in achieving international tobacco control: output of the 48th World Health Assembly, Geneva, May 1995
}

\author{
Derek Yach
}

\section{Introduction}

The World Health Assembly held each year in May in Geneva provides an opportunity to assess progress made in achieving international tobacco control strategies. Visibility given to tobacco control at the World Health Organisation (WHO) and individual member states' public indications of support are useful indications of their commitment to implementing previously supported resolutions and more importantly, an indication of progress in further strengthening international tobacco control strategies.

At the 48th World Health Assembly meeting this past May, a total of 31 countries spoke during the debate on a World Health Resolution that committed countries yet again to a comprehensive, multisectoral, long term tobacco control strategy. What was significant was the large number of countries from emerging economies and the developing world. In particular, six African states spoke in support of the resolution: namely, South Africa, Nigeria, Ghana, Central African Republic, Zimbabwe, and Tunisia ; and five Asian countries (Bangladesh, Philippines, Malaysia, Korea, and China) also supported the resolution. This is in addition to traditional supporters of tobacco control from the advanced industrialised countries.

\section{Support for the development of an international convention to accelerate tobacco control}

It is clear that there is growing international support for an international convention on tobacco control. Strong statements in support of the development of such a convention came form the delegates for Cuba, Canada, Brazil, Malaysia, and Finland. It is likely that over the next few years, this support will not only grow but stands a good chance of resulting in a binding convention that will tackle the international dimensions of tobacco control that have until now been largely ignored. This will in all likelihood require tobacco and tobacco products to be exempted from the terms of the World Trade Organisation.

While all countries were in support of international strategies for tobacco control, the representative from Germany expressed his reservations about support of a ban on tobacco advertising and rather preferred a voluntary agreement between the tobacco industry and the government.

\section{Process in achieving a ban on tobacco} use in all buildings within the $U N$ system

The USA, New Zealand, Canada, and several other representatives expressed their concern about the "inexcusably" slow rate of progress in achieving this already agreed upon ban. While WHO, UNICEF, the World Bank, and UNHCR (UN High Commission for Refugees) had already implemented bans on smoking in their buildings, and UNESCO (UN Educational, Scientific, and Cultural Organisations), the World Intellectual Property Organisation, and the Universal Postal Union were shortly to do so, other UN bodies have yet to implement this. This was clearly evident at the World Health Assembly, which was held in the UN's Palais des Nations. There was an almost continuous presence of tobacco smoke at gathering points outside the main meeting halls of the World Health Assembly. Ashtrays sponsored by tobacco companies were prominently displayed and used even by Ministers of Health from a wide variety of countries. No attempt was made by WHO officials to try to implement a ban on smoking within meeting areas.

Need for greater financial and political commitment to tobacco control

The Cuban delegate echoed many other views in commenting that the resources available for tobacco control by WHO were "meagre". For the 1994/95 regular budget only US\$1.9 million had been allocated to tobacco control despite new evidence emanating form WHO showing that by the 2020 's 10 million people per year would die of tobacco related deaths if current smoking patterns continue.

While many countries expressed strong support for tobacco control, none commented about specific strategies needed to control multinational tobacco companies that operated from their shores. For example the United Kingdom delegation, home to BAT-known for its aggressive marketing in Africa-did not comment at all during the debate. The South African Minister, while being able to report on considerable progress in implementing new 


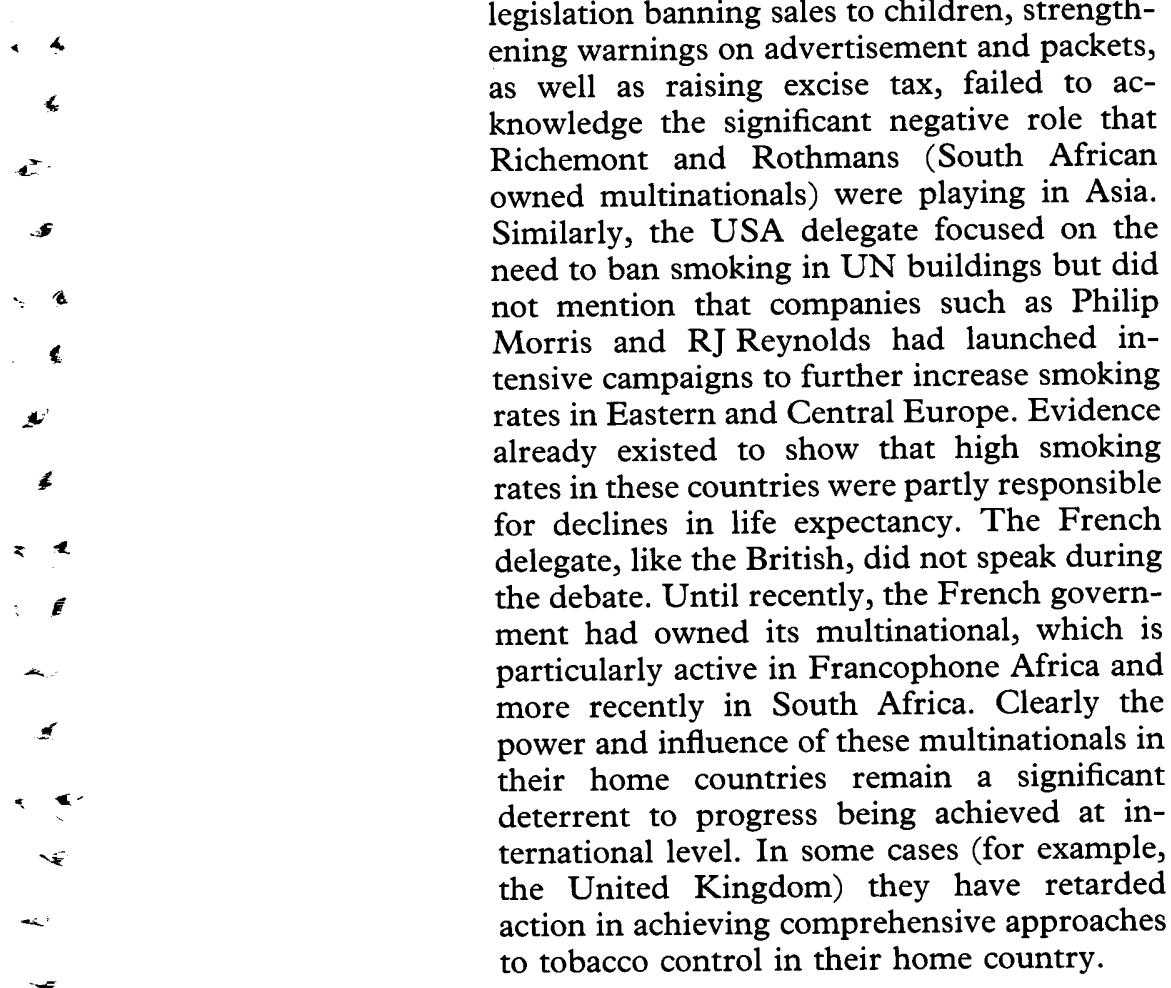

- Progress towards smoke-free airways

$\leftarrow$

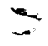

$-$ anti-smoking campaign in schools, and with the Malaysian delegate called for a total ban on tobacco advertising in the Western Pacific by the year 2000. The Central African Republic's delegate and the delegate for Ghana indicated how poor countries remained under pressure from multinationals to accept funding for sports and cultural events from the tobacco industry. Further, the delegate from the Central African Republic called for cigarette packets being exported to developing countries to carry the same warning as they do in their host country.

The South African delegate, in South Africa's first appearance at the World Health Assembly in 30 years, mentioned that Nelson Mandela had received the WHO medal for his contribution to tobacco control. She indicated that the country will continue to play its role not only locally but internationally.

The delegate from Nigeria indicated that while many people still regarded African countries as being beset entirely by infectious diseases, non-communicable diseases were now the major cause of morbidity and mortality in 30 to 60 year olds. This was the reason why they had strengthened their tobacco control programme.

\section{Conclusions}

The 48th World Health Assembly was significant in terms of the number of countries from the developing world that focused on the need for even greater international solidarity in the fight for tobacco control. Further, Canada echoed the views of many when it indicated that WHO must consolidate its leadership in global health, and in tobacco control more specifically. Raoul Uranga, the UN focal point for tobacco control, stressed the constraints under which he was expected to implement an integrated tobacco control strategy within the UN system. One would hope that over the next few years, WHO and the recently appointed UN focal point for tobacco control (placed in the United Nations Conference on Trade) would be given an adequate budget with which to carry out their mandate. It is no longer adequate to continue to provide refined projections of the impact of tobacco use over the next few decades. Failure to take action now will mean that the preventive potential for tobacco control and the gains to global public health will slip further and further into the future. 